\title{
REVIEW
}

\section{Leprosy: applying qualitative techniques to research and intervention}

\author{
JESSICA A. OGDEN, AND JOHN D. H. PORTER \\ Departments of Infectious and Tropical Diseases and Public Health \\ and Policy, London School of Hygiene and Tropical Medicine, \\ Keppel Street, London WCIE 7HT, UK
}

\section{Accepted for publication 1 May 1999}

'Leprosy is, after all, far more than a biomedical phenomenon. It maintains its grip on those human populations already suffering from poverty, inadequate housing, and nutritional deprivation.... Society contributes to the suffering caused by this disease, and society must use every means at its disposal to mitigate that suffering., ${ }^{1}$

\section{Introduction}

Leprosy is far more than a biomedical phenomenon. Although biomedicine has assisted in reducing leprosy prevalence in recent years, one team of researchers note that:

'reduction in prevalence alone is not sufficient as the social consequences of the disease on the life of the patient are often severe and persist even after its cure. The social aspects associated with this disease are therefore as important, if not more important than the biological ones, ${ }^{, 2}$

It is these long-term effects of leprosy on patients, families and communities that have to be addressed, even if the public health goal of eradication is reached.

Leprosy control permits workers in infectious disease control to address health in its broadest sense. Because leprosy patients require long-term rehabilitation, it is important to understand the dynamics of care and support for patients in communities. To address 'health' rather than disease, and to place leprosy within this context of health, requires biomedical workers to consider different perspectives for finding solutions to the care of leprosy patients. If research on leprosy addresses the social, economic and environmental factors that influence people's lives then it can help us develop health systems which more effectively meet communities' health needs.

Correspondence to J.A. Ogden 
A qualitative approach to leprosy treatment and control provides an opportunity for changing prevailing biomedical perspectives through the creation and development of research. This research will need to include disciplines outside of biomedicine. Through developing the research tools and conducting the research, investigators have the opportunity to hear the narratives of leprosy patients and to experience different ways of seeing a health problem. The qualitative approach also questions whether it is possible or even appropriate to change patient behaviour or whether as health care professionals we should provide a service that suits their needs.

It should be stressed here that while social scientists and biological/medical scientists share an understanding of the word and concept of quantitative research, they tend to mean different things when they speak of qualitative research. For those in the medical tradition 'qualitative' tends to refer to data, which are measured on categorical scales-more than/less than, yes/no- and the values on these scales are represented by numbers. Social scientists, on the other hand, will refer to any research which does not use numbers to represent values as qualitative, 'presumably because the data, by their nature unenumeratable (sic), should not be counted $^{3}$. In this paper, we discuss a qualitative approach, which draws upon the principle that the kinds of information sought are not amenable to 'measurement' but can none the less be made intelligible.

In this paper, we explore some principles of qualitative research which address the social and economic consequences of leprosy and leprosy-related disability. We note some pitfalls to be wary of, and the opportunities using these methods and perspectives in programmerelated operations research.

\section{Background to qualitative methods}

Qualitative approaches to research and intervention are well suited to explorations of the social and economic impact of disease and disability on individuals and communities. Qualitative approaches can also help in the development of appropriate and effective interventions to support programme activities of case detection, case holding and social and economic rehabilitation.

As efforts at active case finding and effective treatment of existing cases with multi-drug therapy continue apace and the overall numbers of active leprosy cases continue to fall, locating adequate numbers of patients to yield meaningful or 'significant' statistics will become more difficult. In matters concerning human wellbeing, the variables of importance are often poignantly identified through listening to people's stories. These variables are not always amenable to 'measurement'. In studies of social impact, one needs to know not only the extent and nature of the suffering of individual patients, but to have a comprehensive understanding of the broader social context in which that suffering occurs. Important lessons can be extrapolated from the stories of a carefully selected and relatively small number of informants, and data gleaned from rigorous and systematic qualitative research can provide a sound basis for planning and implementing effective and appropriate treatment and patient support.

\section{Past uses of qualitative approaches in leprosy control}

Qualitative research is not new to leprosy control. Past studies have included work on knowledge and attitudes, treatment-seeking and treatment compliance, ${ }^{1,4-8}$ gender; ${ }^{2,9,10}$ 
beliefs and practices of leprosy patients; ${ }^{11}$ socio-cultural responses to leprosy; stigma issues; ${ }^{4,12-14}$ issues in social and economic rehabilitation ${ }^{1,15}$ and the integration of leprosy control and primary health care.

Although intrinsically interesting, this type of research often looks primarily or exclusively at so-called 'traditional customs' or beliefs, leaves out rigorous investigation of important social structural factors and is not always useful or easily applied to policy and programmes. It can also lead researchers to make 'immodest claims of causality' ${ }^{16}$ by masking the importance of structural inequalities. Rao et al., ${ }^{2}$ for example, note that among Indian women, 'lack of time, money and mobility are more often causes for poor treatment compliance among female (leprosy) patients' than are 'traditional customs'. The better sociological research articles are those which clearly and rigorously address the cultural dimensions of relevance, while placing these within their broader social-structural and/or political-economic context (for leprosy ${ }^{1,2,17}$ ). This orientation is discussed in detail below. Useful guidelines exist for assessing qualitative health research papers. ${ }^{18-21}$

\section{A word (and a warning) about 'qualitative methods'}

It may seem obvious that qualitative research methods are only as good as the scientists using them. An important weaknesses of much qualitative research has been the use of the tools without an understanding of the theoretical principles underlying and underpinning them.

A problem of this 'tool-orientation' relates to the recent proliferation of Rapid Assessment Procedures (RAPs). Known by their supporters as 'practical anthropology', RAPs have been used to gain community and target-group views about the causes of and cures for ill health. They are also used to assess people's reactions to specific interventions. A specific package of techniques has been designed, with the non-specialist in mind, to gain information about health-related beliefs and behaviours. As Scrimshaw and Hurtado ${ }^{22}$ note, obstacles to the use of anthropological approaches and data within the health field have included the long periods normally spent in the field by anthropologists, and the collection of a large amount of theoretical material required within the discipline.

'Another', they write, 'has been that the theoretical concerns of anthropology have not been those of applied health or nutrition programmes. Although the ideal ethnography may be built from both of these elements, a great deal of practical, diagnostic, and applied work can be accomplished in a shorter time and by using a simpler approach.'

'Thus a built-in assumption of these methods is that they leave the theory out, relying instead on a user-friendly toolbox approach to rapidly investigating the sociological dimensions of illness and healing. As Manderson and Aaby ${ }^{23}$ put it:

'...It would be unrealistic to expect theoretically informed anthropological interpretations of social life or cultural issues when the data are collected by researchers without a background in the discipline, notwithstanding the technical skills that may be relatively readily acquired'.

A related problem arises when quantitative researchers employ qualitative tools as if they were the same as quantitative tools. Lacking knowledge about the principles of qualitative 
research, these researchers subsequently get nervous with the small numbers required for conducting qualitative work, and the lack of 'measurement' employed. Thus the counterproductive attempt to measure the unmeasurable begins, producing data of questionable utility.

It is important that qualitative research carried out for leprosy is facilitated and analysed by those with social science training. There are key foundational principles that can be used by health professionals when conceiving a research project in relation to leprosy.

\section{Some basic principles}

From our perspective, the first of the 'basic orientations of qualitative methods' spelled out by Green and Britten ${ }^{24}$ is the most important. They note that qualitative research is based on a commitment to 'naturalism': 'health behaviour' is understood in the context of everyday life. Illness and health are understood and approached differently by lay people than by practitioners. Lay people experience and react to illness in the context of their whole life, while the perspective of the epidemiologist, doctor or pubic health professional is narrowed by the requirements of scientific enquiry or clinical practice. ${ }^{25}$ Health professionals see patients in terms of their illness, whereas the patient is managing the illness within a range of competing needs, priorities, expectations and social roles. Thus our research needs to look beyond the leprosy patient and his experience of illness to see how this experience is influenced by the household and community of that individual. His choices will be crucially framed and constrained by broader social and cultural structures.

Thus, it is important to enquire beyond the experiences of individual patients to address issues in the household and community. It is equally important to look at provision of care and support within the health and social services: what services are available, how they are used and why. Widening the scope still further, these services are themselves resourced and constrained by features in the national and international policy landscape, which may also need to be addressed.

A qualitative approach, therefore, understands the patient and their experience, choices and needs as being nested within many layers of context. The impact of disease and disability, the ability of the patient to adhere to therapy and the choices they makes in relation to advice given, will all be influenced by each layer that surrounds them. The simplest and most straightforward analogy would be of an onion: the innermost portion being the patient herself, each subsequent layer representing a dimension of context for the patient. Research can and should be conducted at each level to develop an understanding that is both comprehensive and useful for policy.

\section{Methods: getting the whole picture}

Throughout this paper we have used the term qualitative approach rather than qualitative methods for two reasons. Firstly we want to stress the importance of conceptual understanding in employing the tools. Secondly, is the point that within a qualitative approach it may be useful and appropriate to use quantitative tools. Rigorous and systematic research on health behaviour should employ a range of methods, held together within an overall framework that takes an essentially qualitative orientation (as described above and in Green and Britten ${ }^{24}$ ). 


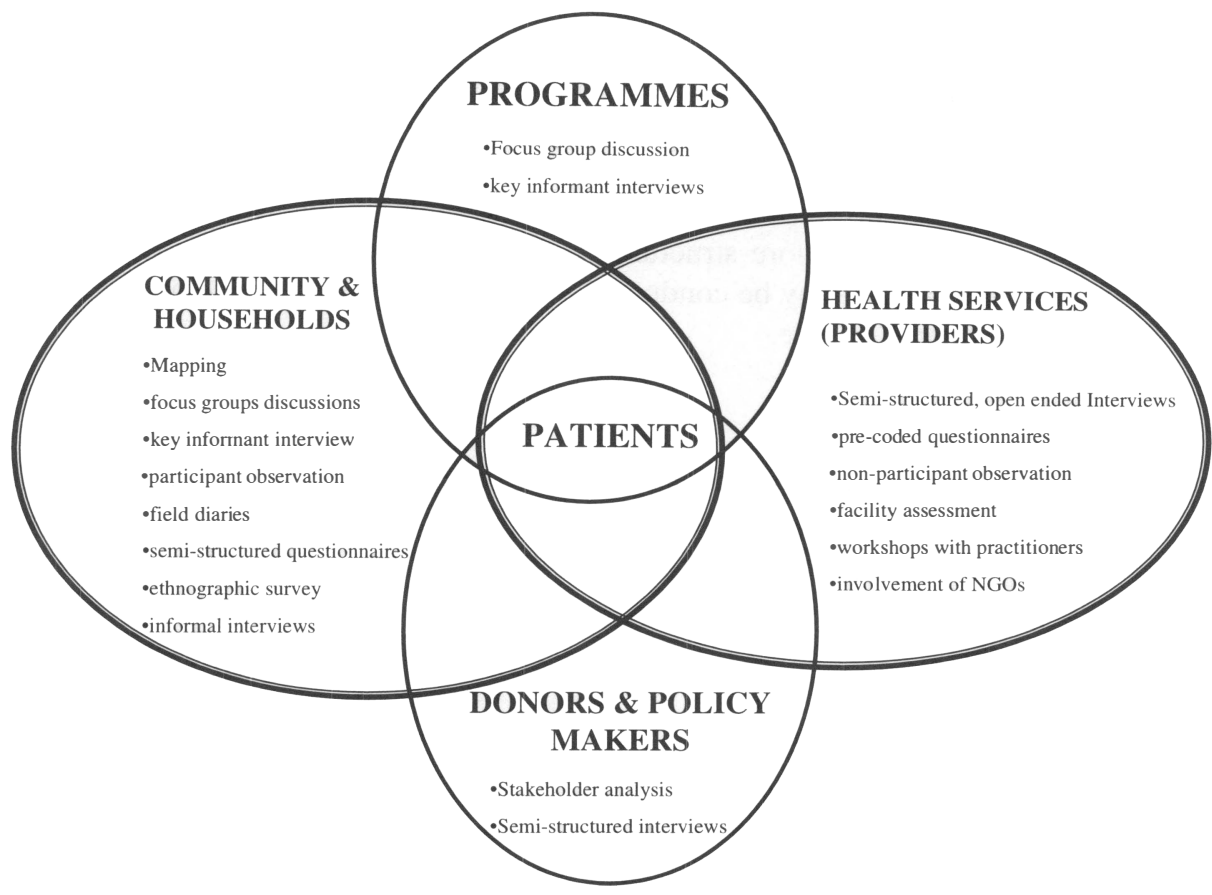

Figure 1. Structure of a qualitative approach

The key domains and methods, which can be employed in this research, are outlined below. While not intended as a formula, this outline can provide a guide to the approach advocated.

\section{IN THE COMMUNITY}

To understand the main resources and constraints to health in the community, mapping, focus group discussions (FGD) and key informant interviews can be undertaken. ${ }^{24,26-28}$ Research teams need to ask: what are the aspects of this community that may influence the wellbeing of leprosy patients? Key questions in addition to mapping may include: what are the main health problems in this area; what are the main sources of care; how do people normally seek treatment; what are the main constraints to health? Participant observations may also be carried out through field diaries recording daily general information.

\section{IN THE HOUSEHOLD}

Household data may be useful: 1) to get more detail on socio-economic and demographic features of the community; 2) to understand approaches to treatment-seeking; and 3) to get further details on specific patient households. For the first and second domains, a semi-structured questionnaire may be appropriate (e.g. an ethnographic survey. ${ }^{29}$ Informal interviews with members of specific patient households can also be carried out (see below). 
AMONG PROVIDERS

Interviews can be carried out among the local providers. The aim is to learn who is treating leprosy patients, how these providers understand, diagnose and treat people with leprosy, the extent to which they refer patients on and what they charge for treatment. Normally a semi-structured, open-ended interview schedule is appropriate, although if there are many providers in the area a more structured pre-coded questionnaire may be employed. Non-participant observations may be conducted to get a further perspective on the treatment process at the key sources of care.

\section{WITHIN THE PROGRAMME}

If the research is to feed into programme operations, it is important to involve the programme at an early stage and to maintain their involvement. FGDs and/or key informant interviews with various cadres of programme staff may help researchers to identify problems and potential within the programme.

\section{AMONG PATIENTS}

Again, it is appropriate to combine methods. It may be useful to conduct some general interviews and observations at drug delivery points and take a sub-sample of those patients for further study. Gathering illness narratives through open-ended, in-depth interviews will be essential and it may be useful to obtain these narratives from a range of patients: those currently on treatment (with various levels of disability), those released from treatment, and those who have left treatment. Case studies can be conducted of a sub-sample of patients, ideally from each of the three categories above. ${ }^{30}$

\section{AMONG POLICY MAKERS AND DONORS}

While this level of analysis may seem abstract, in fact it is quite specific to the problems at hand. A policy or stakeholders analysis may enable the research team to identify potential barriers to uptake of recommendations and also the support for taking forward the changes or projects suggested.

Situating the central research questions about the impact of illness and disability on leprosy patients in their broader social context enables key nodes for intervention to be identified. Programmes based on research of this kind will not focus on changing patient behaviour, but will address specific changes within the health and social services which can be made to better support patients and communities in dealing with this disease and its repercussions.

\section{Conclusions}

The qualitative approach described provides an opportunity to ensure that the broader social, economic and environmental factors affecting people with leprosy are addressed in the provision of appropriate care. The approach also encourages research across disciplines and the inclusion of other important sectors like housing and education. This multi-disciplinarity and cross sectoral approach to infectious disease programmes is being increasingly encouraged to provide innovative means to addressing the control of infectious diseases like leprosy and tuberculosis. ${ }^{31}$ 


\section{References}

I Mull JD, Wood CS, Gans LP, Mull, DS. Culture and 'compliance' among leprosy patients in Pakistan. Soc Sci Med, 1989; 29: 799-811.

2 Rao S, Garole V, Walawalkar S, Khot S, Karandikar N. Gender differentials in the social impact of leprosy. Lepr Rev, 1996; 67: 190-199.

${ }^{3}$ Wallman S and Baker M. Which resources pay for treatment? A mdoel for estimating the informal economy of health. Soc. Sci. Med. 1996; 42(5): 671-679.

${ }^{4}$ Kumaresan, JA, Maganu, ET. Socio-cultural dimensions of leprosy in north-western Botswana. Soc Sci Med, 1994; 39: 537-541.

5 Tekle-Haimanot R, Forsgren L, Gebre-Mariam A, Abebe M, Holmgren, G, Heijbel J, Ekstedt J. Attitudes of rural people in central Ethiopia towards leprosy and a brief comparison with observations on epilepsy. Lepr Rev, 1992; 63: $157-168$.

6 Van de Weg N, Post EB, Lucassen R, De Jong JTVM, Van den Broek, J. Explanatory models and help-seeking behaviour of leprosy patients in Adamawa State, Nigeria. Lepr Rev, 1998; 69: 382-389.

7 Cook A. An urban community's thoughts about leprosy: a survey in Guyana. Lepr Rev, 1982; 53: 285-296.

${ }^{8}$ Reddy NBB, Satpathy SK, Krishnan, SAR, Srinivasan T. Social aspects of leprosy: a case study in Zaria, Northern Nigeria. Lepr Rev, 1985; 56: 23-25.

9 Pearson M. What does distance matter? Leprosy control in West Nepal. Soc Sci Med, 1988; 26: 25-36.

10 Ulrich M, Zulueta AM, Caceres-Dittmar G, Sampson C, Pinardi ME, Rada EM, Aranzazu N. Leprosy in women: characteristics and repercussions. Soc Sci Med, 1993; 37; 445-456.

11 Opala J, Boillot F. Leprosy among the Limba: illness and healing in the context of world view. Soc Sci Med, 1996; 42: 3-19.

${ }^{12}$ Douglas M. Witchcraft and leprosy: two strategies of exclusion. Man, 1991; 26: 723-736.

13 Gussow Z, Tracy GS. Status, ideology, and adaptation to stigmatized ilness: a study of leprosy. Human Organisation, 1968; 27: 316-325.

14 Wilson-Moore M. 'Alas, I am undone for I am a leprosy patient'. Applying anthropological methods to planned change. Can J Dev Stud, 1997; 18: 485-502.

15 Gershon W, Srinivasan GR. Community-based rehabilitation: an evaluation study. Lepr Rev, 1992; 63: 51-59.

${ }^{16}$ Farmer P. Social Scientists and the 'new' tuberculosis. Soc Sci Med, 1997; 44: 347-358.

17 Bijleveld I. In reality: a medical anthropologist's reservations about the viability of leprosy control within Primary Health Care. Lepr Rev, 1982; 53: 181-192.

18 Mays N, Pope C (eds). Qualitative research in health care. London: BMJ Publishing Group, 1996.

19 Blaxter M. Criteria for the evaluation of qualitative research papers. Med Sociol News, 1996; 22: 68-71.

${ }^{20}$ Dowell J, Huby G, Smith C (eds). Scottish consensus statement on qualitative research in primary health care. Dundee: Tayside Centre for General Practice, 1995.

21 Boulton M, Fitzpatrick R, Swinburn C. Qualitative research in health care II. A structured review and evaluation of studies. J Eval Clin Prac, 1996; 2: 171-179.

22 Scrimshaw SCM, Hurtado E (eds). Rapid assessment procedures for nutrition and primary health care. Tokyo: The United Nations University, 1987.

${ }^{23}$ Manderson L, Aaby P. An epidemic in the filed? Rapid assessment procedure and health research. Soc Sci Med, 1992; 35: 839-850.

${ }^{24}$ Green J, Britten N. Qualitative research and evidence based medicine. BMJ, 1998; 316: 1230-1232.

25 Wallman S. Ordinary women and shapes of knowledge: perspectives on the context of STD and ADS. Public Understandings of Science, 1998; 7: 169-185.

${ }^{26}$ Gibbs A. Focus Groups. Social Research Update No, 19. University of Surrey, 1997.

27 Kitzinger J. Introducing focus groups. BMJ, 1995; 311: 299-302.

28 Coriel J. Group interview methods in community health research. Med Anthropol, 1995; 16:, $193-210$.

29 Wallman S. Kampala women getting by: wellbeing in the time of AIDS. London: James Currey, 1996.

${ }^{30}$ Mitchell CJ. Case and situation analysis. Soc Rev, 1983; 31: 187-211.

31 Porter JDH, Ogden JA, Pronyk P. The way forward: an integrated approach to tuberculosis control. In: Porter JDH and Grange JM, eds. Tuberculosis - an interdisciplinary perspective. London: Imperial College Press, 1999: pp. $359-378$. 